The ideal and actual number of children during fertility decline

The child deficit and the changing value of children in Asia

Since the 1960s, Asia has experienced a dramatic decline in fertility rates. Philip Morrison, Professor Emeritus at Victoria Zealand, asks whether this Zealand, asks whether this by a reduction in the value of children as inferred from the European experience. If so, on might expect a convergence of the ideal and actual family size and a gradual elimination of the child deficit - the difference between the ideal number of and the number they end up raising. Data from the World Values Survey suggests only a minor reduction in the value of children but rising constraints on the realisation of the idea family size have sustained rather than reduced the child deficit. Professor Morrison ar the fertility transition the instrumental value of the child (their net return in economic terms) declines faster than the immanent values (children for children's sake), thereby widening rather than narrowing
the gap between the ideal and the gap between the ideal
actual number of children. hilip Morrison, Professor In most Asian countries, average family Emeritus at Victoria University
of Wellington in New Zealand has been conducting research to understand whether changing values may be leading to changing family size decisions that are associated with declining fertility rates across Asia. His findings have been published as chapter 14: 'The child deficit and the changing value of children in Asia' in Poot \& Roskruge (eds) (2020), Population change and impacts in Asia size has more than halved over the past six decades. This decline has been decline is closely linked to the decisions women are making about marriage and motherhood. These decisions include whether to marry, when to marry when to have children and how many childre decisions have been influenced by widening access women now have to further education and employment in the formal sector.

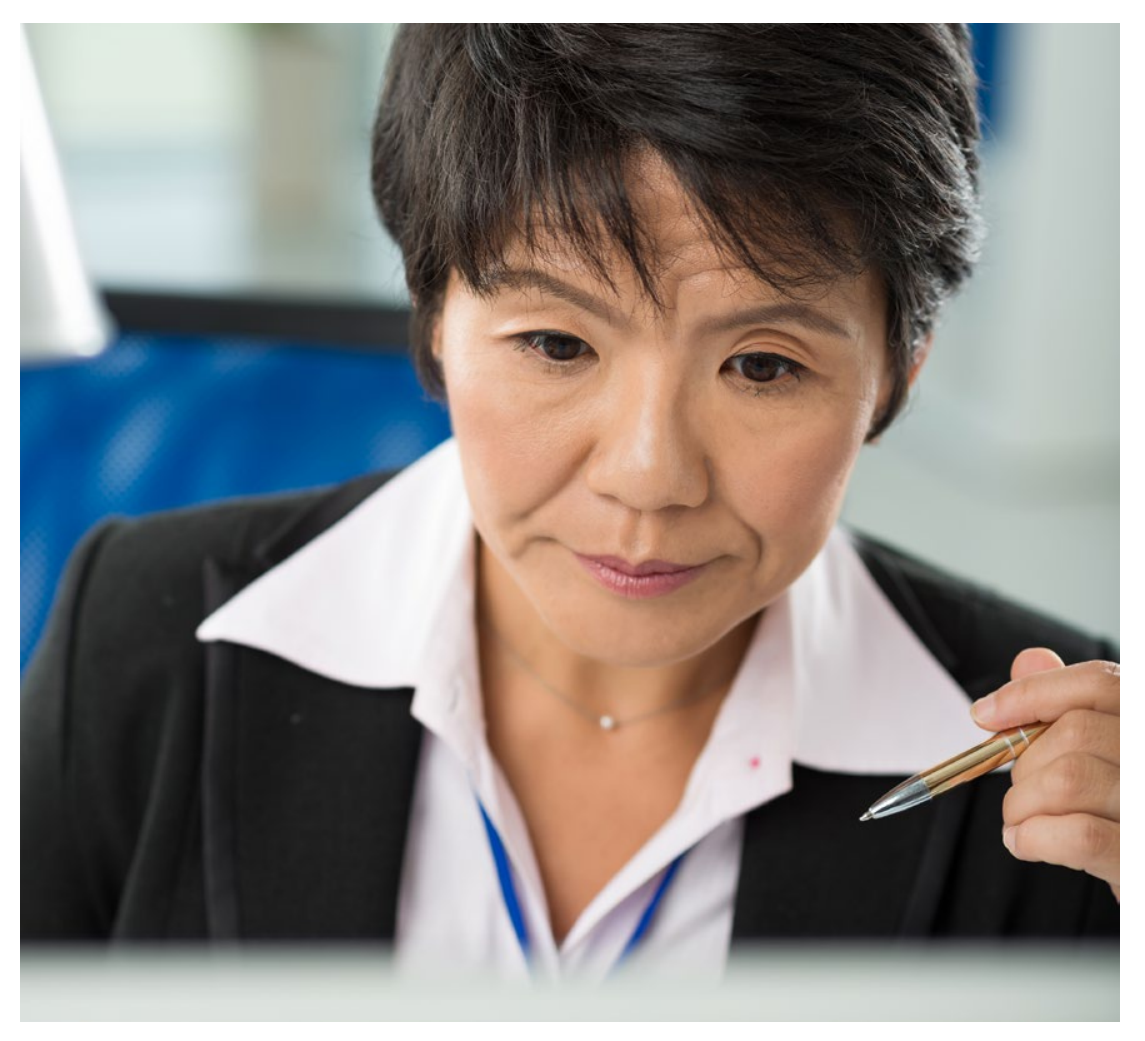

"A woman has to have child
agree with this statement. to bear. In these regions of $A$ sia, these

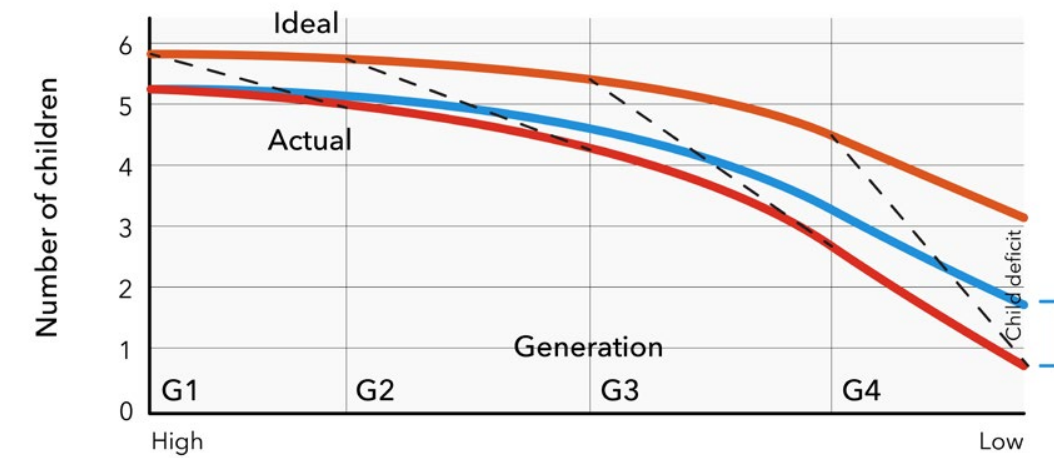

The value of the child (motherhood) Fig. 1: During the fertility transition, the actual number of children falls faster than the ideal. The
nonlinear relationship between the number of children and the value of the child reflects the
diminishing returns to children. The ideal and the actual number are measured at different points diminishing returns to children. The ideal and the actual number are measured at different points
over the life course: the ideal at the beginning of a woman's reproductive life and the actual at the end. The gap between the ideal and the actual expands over the generations $(G 1, \ldots, G 4$ ), the
difference being depicted by the dashed lines. The gap labelled' single' denotes fewer children as

Within other regions of Asia - mainly decisions about marriage and

motherhood do not seem to be having the same influence on the fertility rate. Yet in these countries, there has also been a marked decrease in average family size. Prof Morrison set out to investigate what other factors might be driving the decline in fertility rates in Asia. He writes: "By middle age, individuals living in Asia will realise far ewer children than they wanted as young adults."

\section{VALUE OF THE CHILD}

iternal motivational drivers, such as the changing value woman are placing may also drive decisions about whether the ages of 15 years and 90 years of

realised family size). This gap between the ideal and the actual is what Prof Morrison refers to as the 'child deficit'.

Prof Morrison set out to explore the presence of the 'child deficit' in Asia using data from the World Values Survey (www.worldvaluessurvey. org). This survey dates back to 198 and gathers information on the changing values held by people in a wide range of countries. The survey data is compiled by an internation network of social scientists. Using the data from 1990-2010, Prof Morriso analysed changes in values in two Asian countries where the relevant questions were repeated. Japan

and how many children to raise. Prof values regarding
ideal family size ideal family size
are internalised by time in women's views of the role of motherhood within their lives.

age were asked to respond to the often reflect the number of siblings within a household in which a child is raised. What is more, they are likely to change far more slowly than external constraints which impact on family size. Parents may therefore end up with a gap in the number of children they fanily size) and the nave (their ideal they ever statement that "A woman has to have children to be fulliled". The response options were either "Not necessary" or "Neep chlden". The results showed "Nop In the agreeng with the statement. and 1994, a total of 71.5 percent of and 1994, a total of 71.5 percent of children to be essential for their fulfilment. By the next decade, this figure had dropped to 64.9 percent of Korea. Although limited to two Asian countries, these results reflect a steady change over time in these women's views of the role of motherhood within their lives. Prof Morrison concludes that "in an age of planned parenthood most parents now weigh up the costs and returns before deciding on having an additional child".

\section{IDEAL AND ACTUAL}

\section{NUMBER OF CHILDREN}

In order to obtain an estimate of the child deficit, Prof Morrison ran two sets of regression models, one to estimate the probability of each ideal family size and the other to estimate the The average predicted probability fro the first regression for each country was subtracted from the predicted

probability from the second regression and related to the country's total fertility rate. The result showed that the estimated child deficit rose as a country's average family size declined.

The first set of regressions was designed to estimate the probability a young woman would prefer not to have stimate one child as the ideal and so forth. The equation used as its anguments the response to f child her age (between 20 and 35 years) whethe (becwen 20 and 35 years), ret whe her a tertary qualification or the 14 country-waves she was sampled in. This last variable the country, had a on the ideal as did the number of children already

in the family. When it came to those respondents whose ideal extended to three or more children, Prof Morrison found very low probabilities in the high fertility countries of Bangladesh and India but surprisingly high probabilities in low-fertility countries such as Japan, South Korea and Singapore. The value had a profound infl tonotherhood at least one child (controlling for the 


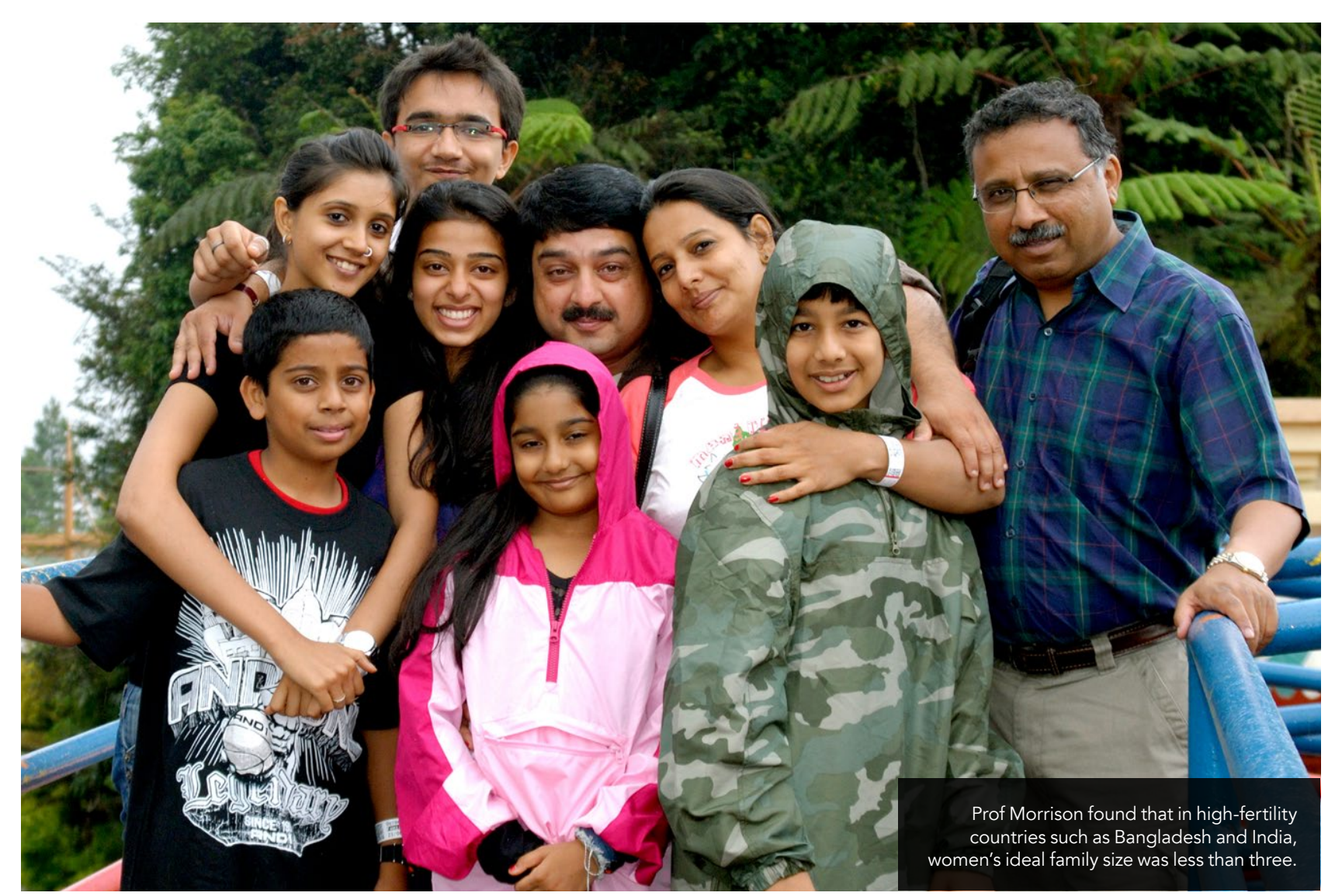

other variables in the model) but had a decreasing influence as the ideal number fell. In other words, the value of the child, as defined above, had a rapidly diminishing influence on the ideal number of children beyond one.

The second set of regressions applied to middle-aged women produced estimates of the probability of having raised Who children, one child and so the diminished role that the value of the child played when it came to explaining who actually had children as opposed to simply expressing voicing an ideal number. A noticeable difference from the case of the ideal number is the role played by $\begin{array}{ll}\text { tertiary education on the actual number. } & \text { out with certain expectations about } \\ \text { Holding a tertiary degree did not } & \text { their ideal family size, circumstances }\end{array}$ Holding a tertiary degree did not influence young adult's ideal number negative effect in realsing successive family sizes. Similarly, in the case of employment, middle-aged women children. This feature was not observed when it came to young women

\section{FERTILITY DECLINES}

VALUES OR CONSTRAINTS? Decisions about ferlity require trade-oms wh posive and negative society. While young adults may set

of day. These factors include, amongst others, the urban environment, standard of living, income, and epportunities to realise their expectations and potential as parents.

The very presence of a high child deficit in low-fertility countries suggest a builtin preference for larger family size whic contemporary living arrangements are Tourban hatisy tabour market institutions and priorites which many While young adults may set out with certain expectations about their government find hard to address. between the values ideal family size, circumstances and reflected in ideal environmental constraints result in young family size and their people compromising these expectations family size is also it implies for wuture it implies for future population growth. The contemporary challenge in developing pro-natalist their ideal family size, cicumstances policy will be to identify those levers and environmental constraints result that will allow the women (and men) in couples comproming these tor

\section{Behind the Research}

Professor Philip S. Morrison

E: philip.morrison@vuw.ac.nz T: +64040272828811

Research Objectives Prof Morrison is examining one of the consequences of fertility decline: the gap between the number of children young parents want
and the number they end up raising - the child deficit.

\section{Detail}

Professor Philip Morrison
c/o School of Geography

Clo School of Geography
Evvironment and Earth Sciences

Victoria University of Wellington

$\mathrm{PO}$ Box 600
Wellington,

Wellington,
New Zealand

\section{References}

- Morrison, P.S. (2020). The child deficit and the changing Papulation change and in Pacts in Asia and the Pacific. New frontiers in Regional Science: Asian perspectives, 30 , 313-339. Singapore: Springer. Available at: eBook ISBN:
978-981-10-0230-4; https://www. doi.org/10.1007/978981-10-0230-4 - World Values Survey [online]. Available at: www.
worldvaluessurvey.org [Accessed 07/08/2020]

\section{Examples of the author's related work}

(2011). Local expressions of subjective well-being: the New Zealand experience. Regional
Studies, 45(8), 1039-1058. Available at: https://doi. ride in the city. Region, 3(2), 103-124. Available at: https://doi.org/10.18335/region.
v3i2.130. The second editor introduces this issue in http:/// youtu.be/6D 62 rFZJtpA (2017). Human values, subjective wellbeing and the metropolitan region. 3), 325-337. Available at: http:// dx.doi.org/10.1080/00343404.2017.1331036 Scienze Reg. (201: 18(3)651-656. Availetle at: hellbeing. Morrison, P. S. (2020). Wellbeing and the region. In Fischer, M.M. and Nijkamp, P. (eds.). Handbook of regiona hittps://doi. org/10.1007/978-3-642-36203-3 16-1 - Morrison, P.S., Burger, M.J., Hendricks, M. and Hoogerbrugge, M.M. (2020). Urban-rural happiness differentials across the world. Chapter 4. In: Helliwell, J.F., Layard, R., Sachs, J.D. DeNeve, J-E. (eds.) WORLD
HAPPINESS REPORT 2020, 67-94. Available at. http./ worldhappiness.report Readers may contact the author directly for copies of the above articles as well as any others listed in www.victoria philip-morrison University of Wellington and a PhD
degree from the University of Toronto

Funding The author acknowledges Prof James Renwick who supported publication

\section{Personal Response}

How is the child deficit likely to impact on women,
children, societies and regions with ultra-low fertility rates?

III The nature of the impact depends on whether one a whole. The expanding body of research on the impact of children on the well-being of adults, both fathers and mothers, shows marked variation depending on the stage My research on the child deficit shows that the response to the value of the child question has the most impact on the decision to have the first child but carries diminishing weight in turn shows that the well-being impact of the child varies depending on the demands they place, along with other re stage considerations, on the parents themselves. The
returns to childbearing change with the age of the child, the age of the parent and grandparent as well as the socio-

The impact of the child deficit on the society as a whole material and social relationship consequences for parents been widely considered Of particular interest is how it informs the development of pro-natalist policies in
countries facing falling marriage rates, smaller families and an aging population. A major question is the degree changing the ideal and can reduce the child deficit by generations and the degree to which those changes will

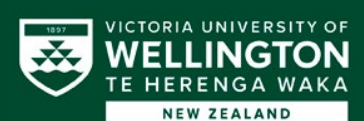

